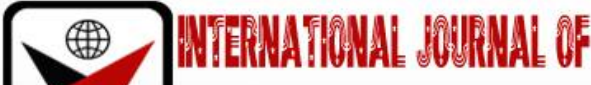

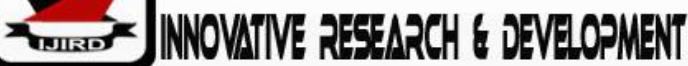

ISSN 2278-0211 (Online)

\section{The Effect of Recruitment and Selection Pattern on Institutional Efficiency: A Study of Five Selected Federal Tertiary Institutions in North Eastern Nigeria}

\author{
Shadrach Brandford Adams \\ Lecturer, Department of Social Sciences Unit, School of General and Management Studies, \\ Federal Polytechnic, Bali, Taraba State, Nigeria
}

\begin{abstract}
:
This study examines the effect of recruitment and selection pattern on institutional productivity with focus on five selected tertiary institution in the North eastern Nigeria. It corroborates submissions in literature that recruitment and selection pattern is pivotal to the success of an organization. The findings of the study reveal that majority of the respondents believed recruitment and selection pattern in their institutions are tainted by the triangular fault lines of ethnicity, religion, regionalism and other parochial considerations instead of merit. Consequently, since most of the employees are connected to the leadership of the institution, there seems to be lack-luster attitude on the part of the leadership to impartially enforce rules and uncompromisingly maintain standards which are critical to institutional efficiency and productivity. The study adopted a survey research design and employed both primary and secondary data to address the major research question. The population of the study was both academic and non-academic staff of the selected tertiary institutions. Result was determined using tools like bar-chart and simple percentage with the aid of excel software statistical analysis. The study concludes that organizations would be more efficient and productive if the tenets of merit and impersonality are upheld in their recruitment and selection process. This by implication will mean that only the suitably qualified candidates are recruited or employed irrespective of their ethnic, religious or regional background. Consequently, they will bring to the table their expertise which will enhance organizational efficiency.
\end{abstract}

Keywords: Recruitment, selection, institutional, efficiency, productivity, tertiary institutions

\section{Introduction}

Efficiency and productivity are the topmost priority of modern organizations. Even though all components critical to attaining efficiency in an organization are important; one aspect that has received recent attention in literature is human resource. This is because in the wake of the challenges and opportunities spurred by globalization and its attendant consequences on work places, organizations need to upgrade in tune with changing times to remain relevant. This can be done by injecting new ideas, skill sets and adopting other conventional methods which makes recruitment and selection process very vital. Consequently, people are a very important component because they offer their services, values and equally contribute to the overall growth of the organization if judiciously managed.

Studies have shown that effective recruitment and selection process leads to better company result. Thus, organizational performance is hinged on the approach which the organizations adopt in the recruitment and selection of its employees. In the same vein, the quality of product and services is improved when the best employees are hired and retained. The more objective the recruitment and selection criteria, the better the organizational performance (Burnley, 2020; Tizhe et al, 2017; Ekoaba et al, 2015; Ezeali \& Esiagu, 2010; Sakar \& Kumar, 2007). But one area that has not received much attention in literature on recruitment and selection process especially in Nigeria is the influence that factors like ethnicity, regionalism and religion might have on the process of recruitment and selection vis-a-vis their effects on institutional efficiency. In a collectivist society like Nigeria, these sensitive triangular faultlines in many cases underscore official actions including recruitment, employment and postings. Research has equally shown that culture (which encapsulates these faultlines) has a substantial influence on every aspect of the institution; employees' work life, preferences on work standards, attitudes regarding punctuality and datelines, commitment to work or the organization, justice perception, group work, including conformity, policy formulation process among others (Gurdham, 2011, Li \& Karakowsky, 2002, Paul, 1990). Even though, sometimes these might not necessary be culturally related influences (Sims, 2009). Impliedly, nepotistic tendencies spills and permeates into many work places where merit and requisite competences are jettisoned. This results into a situation where you have a square peck in a round hole undermining the efficiency of the organization. 
In the light of the above, the evolutionary process of many public institutions in Nigeria possibly aligned with some aspects of Tuckman's (1965) group development model; forming, storming, norming, performing and adjourning. The formative stages of most tertiary institutions are mostly determined by the prerogatives of chief executives who are probably given the mandate to assemble their management teams including recruitment of the employees. In several instances, recruitment, appointment, placement, posting and promotion of employees are possibly influence by patronage or the triangular factors of religion, region and ethnicity mentioned above. In some cases, these are done with no regard for merit. Thus, the perennial problem of institutional waste, absenteeism, late coming, delay in the processing of files, lack of due diligence and selective bias in processing information, communication gap, poor supervision, mishandling of confidential information and placing of round peck in a square hole, flaws in decision making process, lack of tradition of impartial leadership; lack of norms requiring methodical procedures for scrutiny of favored solutions; lack-luster attitude on the part of the leadership of the institution to impartially enforce rules and uncompromisingly maintain standards which are critical to institutional efficiency and productivity have become a defining feature of some Nigeria's public institutions (Brandford \& MacDonald, 2020). This study examines the effect of recruitment and selection pattern on institutional efficiency with focus on five selected federal tertiary institutions. It attempts to examine how a recruitment and selection pattern tainted by the triangular faultlines of ethnicity, religion and regionalism or other parochial consideration can potentially undermine institutional efficiency.

\section{Methodology}

The study is a mixed method which employed both primary and secondary data to answer the research question. It adopted survey research design and usedfive-point Likert scale questionnaire to obtain primary data. Likert Scale according to Likert (1932) is used to gauge attitudes, values and opinions. Thus, the study only analyzes the opinions of the respondents which constitute their perception of the pattern of recruitment in their respective institutions. The population of the study was both academic and non-academic staff of the five selected federal tertiary Institutions in north eastern Nigeria. Therefore, using stratified random sampling, about 980 copies of questionnaire was administered to 980 respondents who constitute the sample size. In addition, out of the total number distributed, only 922 copies were validly filled and retrieved. However, the number of copies (58) not retrieved did not affect the overall outcome of the data analysis. Result was determined using tools like bar-chart and percentage with the aid of excel software statistical analysis.

\section{Discussion}

Recruitment is the process of gathering qualified applicants for available positions within an organization (Mathis, 2004). It entails deciding whether to employ the qualified applicants or to reject them. Selection involves choosing the most suitable applicants who satisfy the requirements for a particular job. The practice of selection is a decision-making activity or a psychological calculation of appropriateness (Price,2004). Hence, it may be prune error of judgment leading to subjective decision if not properly handled. One of the vital roles played by the human resource management unit of any functional institution or organization is recruitment and selection. This is because recruiting and selecting the wrong candidates may have a rippling effect on the productivity and the effectiveness of the organization (Angyango et al, 2018; Ekwoaba, 2015; Gamage, 2014; Ofori \& Aryeetey, 2011). Therefore, a sound manpower plan programme logistically follows a well-drawn recruitment strategy. This point is corroborated by Tizhe et al (2017) who believes that the quality of the organizational performance depends upon the quality of employees which is determined by recruitment policies and practices in organization. Organizations that adopt appropriate selection processes are guaranteed to hire employees with the right skills and levels of confidence for a particular job (Pfeffer, 1994; Huselid, 1997). Some researchers found that prerogative recruitment and selection practices positively affect organizational performance (Harel \& Tzafrir, 1996; Delany \& Huselid, 1996). Delany and Huselid (1996) found that effective recruitment and selection processes positively affect organization performance. By studying the employee recruitment, retention, and performance strategies in the Nigerian civil service, Gberevbie (2010) emphasized the importance of adopting appropriate employee recruitment and retention strategies to improve organizational performance but fall short identifying why such strategies should be adopted. Other researchers suggested that a significant and positive relationship exists between recruitment/selection and organization performance (Terpstra \& Rozell, 1993; Harel \& Tzafrir, 1996; Gberevbie, 2010).

The foregoing submissions ties into theoretical premise like Human Capital Theory, Resource Based View Theory and Equity Theory. For instance, Human Capital theory as advocated by the famous economist Adam Smith (1723-1790) in Teixeira (2002) who opined that people are fixed capitals just like machine because they have skills and useful abilities that has genuine cost and yields profits. Additionally, the main thrust of human capital theory according to Armstrong (2006) is that people and their collective skills, abilities and experience, coupled with their ability to deploy these in the interests of the employing organization, are now recognized as making a significant contribution to organizational success and also constituting a significant source of competitive advantage.

Equally, Resource Based View (RBV) as propounded by Barney (1991) suggests that sustainable competitive advantage is attainable when firms have a human resource pool which cannot be imitated or substituted by rivals. Accordingly, firms should constantly evaluate their workforce to ensure that they have the right people with the right skills in the right places to ensure sustained competitive advantage (Barney, 2001) and when this is not the case, firms should make-up for the shortfall by employing appropriate recruitment and selection criteria. The theory maintained that the major part of any firm's strength or weakness stem from the calibre of the people employed and the quality of their working relationships. To this end, Boxall (1998) revealed that firms which recruit and retain exceptional individuals have the capability of generating human capital advantage. According to Sparrow et al., (2002), technology and capital can be 
acquired by most firms any time, for a price, but it is not easy to acquire a ready pool of highly qualified and motivated employees.

Consequently, the foregoing theoretical submissions underscore the pivotal roleshuman expertise or skills plays in the performance of an organization. Thus, in terms of recruitment and selection pattern in an organization, caution must be taken in order to get the right manpower to remain relevant. In the light of the foregoing, a study by Anyango et al (2018) concludes that the ability of an organization to objectively recruit and select staff determines how well it can perform in the job market. Also, Djabatey (2012) argues that for an organization to gain a competitive edge in the market, it must have the right staff. The right staff can only be recruited through a fair and objective recruitment and selection process.

\section{Findings}

\subsection{Question 1}

The recruitment and selection pattern of many employees in your institution is mostly characterized by kin-ship and other in-group considerations like religion and region instead of merit.

\begin{tabular}{|c|c|c|c|c|c|c|c|c|c|c|c|}
\hline QUEST. No & TOTAL & SA & \% & A & \% & NAD & \% & SD & \% & D & \% \\
\hline Question 1 & 922 & 182 & $20 \%$ & 283 & $31 \%$ & 148 & $16 \%$ & 119 & $13 \%$ & 190 & $20 \%$ \\
\hline
\end{tabular}

Table 1: Distribution of Responses and Their Percentages

Key: $S A=$ Strongly Agree $A=$ Agree $N A D=$ neither Agree or Disagree $S D=$ Strongly Agree D=Disagree Source: Brandford, 2019 (Excel Analysis)

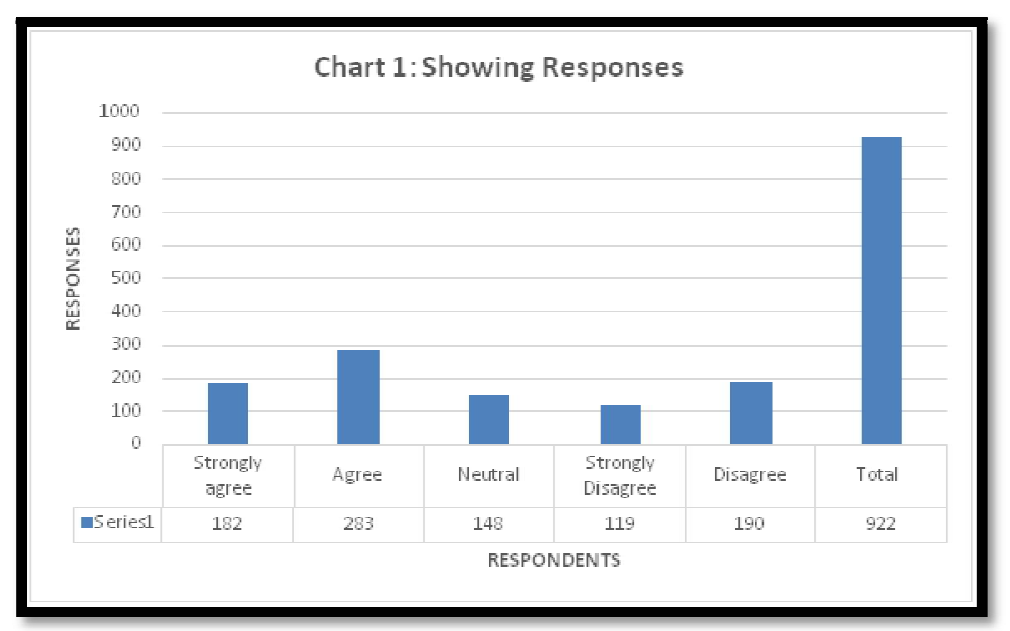

Figure 1

Source: Brandford, 2019 (Excel Analysis)

The table and chart above show responses on perceived recruitment and selection pattern of the selected tertiary institutions studied. The distribution of the responses shows that majority of the respondents representing $31 \%$ Agree that the recruitment and selection process in their institution is characterized by kin-ship and other in-group considerations like religion and region instead of merit. Equally, if the total number of respondents who strongly Agree $(20 \%)$ is added to the number of those who agree, it will show that $51 \%$ of the respondents responded in the affirmative while 33\% (representing the number who disagree and strongly disagree) responded in the negative. Contrastingly, only $16 \%$ of the respondents remained undecided or neutral, this is insignificant compared to $51 \%$ comprising of positive responses. Therefore, it can be said that the recruitment and selection pattern of many employees across the institutions studied are mostly characterized by kin-ship and other in-group considerations like religion and region instead of merit.

\subsection{Question 2}

Your institution has instances 'round peck in a square hole' where some employees are wrongly placed in terms of job description just to accommodate them.

\begin{tabular}{|c|c|c|c|c|c|c|c|c|c|c|c|}
\hline QUEST. No & TOTAL & SA & \% & A & \% & NAD & \% & SD & \% & D & \% \\
\hline Question 2 & 922 & 157 & $17 \%$ & 394 & $43 \%$ & 202 & $22 \%$ & 99 & $11 \%$ & 70 & $7 \%$ \\
\hline
\end{tabular}

Table 2: Distribution of Responses and Their Percentages

Source: Brandford, 2019 (Excel Analysis) 


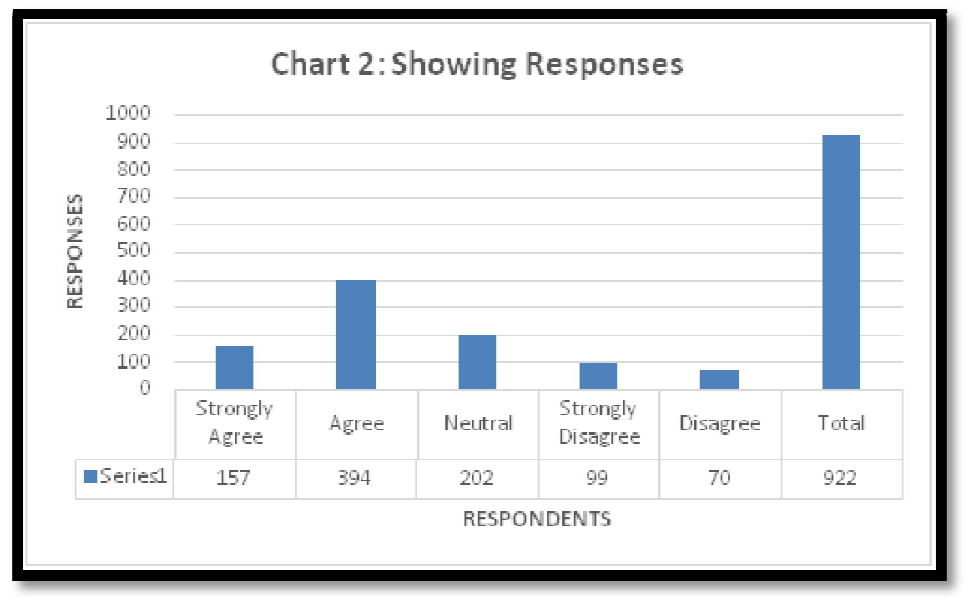

Figure 2

Source: Brandford, 2019 (Excel analysis)

In the above table and chart, majority of respondents representing $43 \%$ agree that some employees in their institution are wrongly placed just to be accommodated. However, even though the percentage of number of neutral respondents' hovers around $22 \%$ which is a lot. Yet if the percentage of respondents who strongly agree (17\%) is added to those of Agree (43\%) it will show that $60 \%$ of the respondents have responded positively in the affirmative. On the other hand, the respondents who either disagree (7\%) or strongly disagree $(11 \%)$ if added will show that $18 \%$ of the respondents have responded negatively. Therefore, it can be said that some employees across the institutions studied are wrongly placed just to be accommodated.

\subsection{Question 3}

Absenteeism, late coming to work and lack of commitment to task are very common in your institution.

\begin{tabular}{|c|c|c|c|c|c|c|c|c|c|c|c|}
\hline QUEST. No & TOTAL & SA & $\mathbf{\%}$ & A & $\mathbf{\%}$ & NAD & $\mathbf{\%}$ & SD & $\mathbf{\%}$ & D & \% \\
\hline Question 3 & 922 & 141 & $15 \%$ & 469 & $51 \%$ & 159 & $17 \%$ & 70 & $8 \%$ & 83 & $9 \%$ \\
\hline \multicolumn{10}{c|}{ Table 3: Distribution of Responses and Their Percentages : Brandford, 2019 (Excel Analysis) }
\end{tabular}

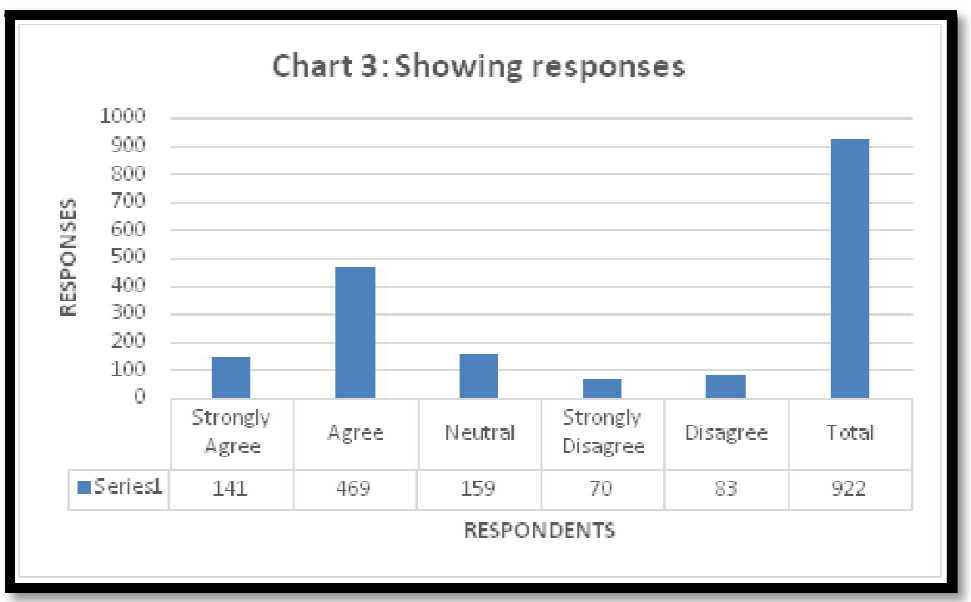

Figure 3

Source: Brandford, 2019 (Excel analysis)

From the table and the chart above, it can be seen that majority of the respondents constituting $51 \%$ agree that absenteeism, late coming to work and lack of commitment to task are very common in their institutions. When the number of those who strongly agree (15\%) is added to those who agree (51\%) it will show that $66 \%$ of the respondents responded in the affirmative. While 17\% remained undecided, $17 \%$ put together eitherstrongly disagree or disagree. It can be said therefore that absenteeism, late coming to work and lack of commitment to task are very common across the tertiary institutions.

\subsection{Question 4}

There are instances where erring employees always go scot free because of their connections with some members of the top management. 


\begin{tabular}{|c|c|c|c|c|c|c|c|c|c|c|c|}
\hline QUEST.No & TOTAL & SA & \% & A & \% & NAD & \% & SD & \% & D & \% \\
\hline Question 4 & 922 & 172 & $19 \%$ & 437 & $47 \%$ & 141 & $15 \%$ & 98 & $11 \%$ & 74 & $8 \%$ \\
\hline
\end{tabular}

Table 4: Distribution of Responses and Their Percentages

Source: Brandford , 2019 (Excel Analysis)

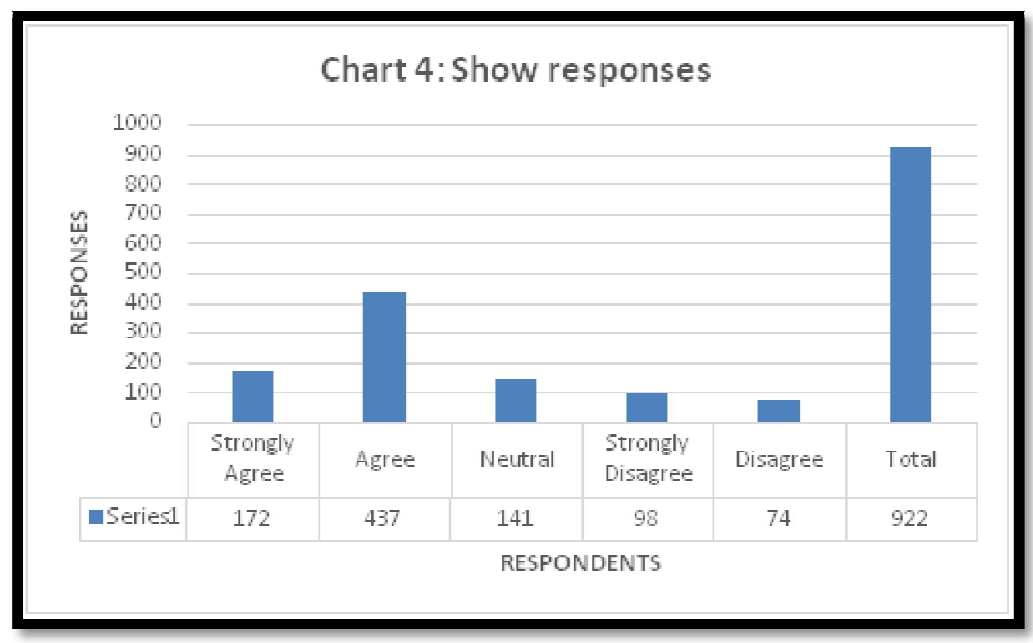

Figure 4

Source: Brandford , 2019 (Excel analysis)

The table and the chart shows majority of respondents comprising $47 \%$ agree that some erring employees always go scot free because of their connections with some members of the top management. As can be seen, the respondents who responded in the affirmative constitute $65 \%$ when those of strongly agree (19\%) is added to those who agree (47\%). While $15 \%$ are undecided, $19 \%$ put together either strongly disagree or disagree. Therefore, it can be said that some erring employees across these tertiary institutions always go scot free because of their connection to members of the top management.

\subsection{Question 5}

Your institution would've been more efficient if the tenets of impersonality and merit are upheld in terms of appointment, posting and daily administration.

\begin{tabular}{|c|c|c|c|c|c|c|c|c|c|c|c|}
\hline QUEST. No & Total & SA & \% & A & \% & NAD & \% & SD & \% & D & \% \\
\hline Question 5 & 922 & 260 & $28 \%$ & 471 & $51 \%$ & 131 & $14 \%$ & 41 & $4 \%$ & 19 & $3 \%$ \\
\hline
\end{tabular}

Table 5: Distribution of Responses and Their Percentages

Source: Brandford , 2019 (Excel Analysis)

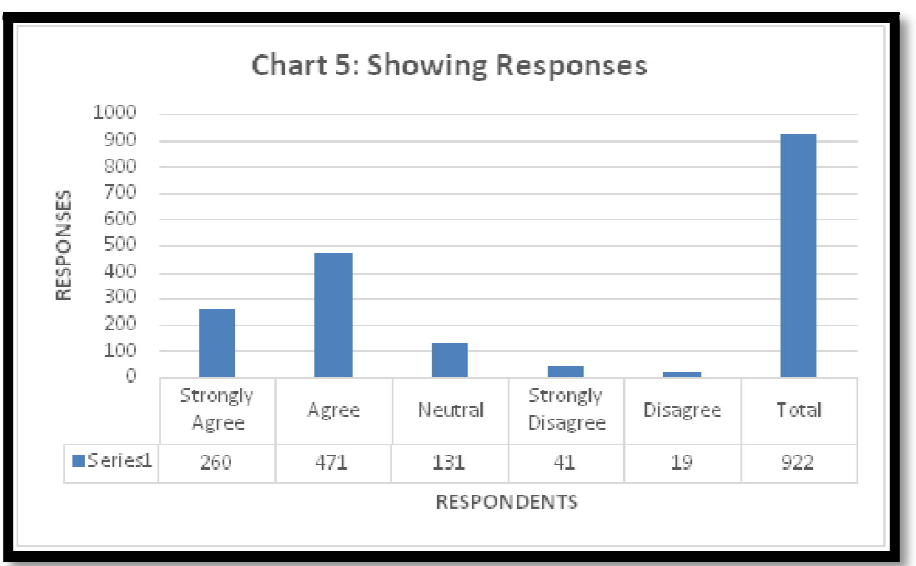

Figure 5

Source: Brandford, 2019 (Excel analysis)

From the table and the chart above, it can be seen that majority of the respondents constituting $51 \%$ agree that their institution would've been more efficient if the tenets of impersonality and merit are upheld in terms of appointment, posting and daily administration. Equally, when the number of those who strongly agree (28\%) is added to those who agree, it will mean that $79 \%$ of the respondents responded in the affirmative. While $14 \%$ remain undecided, $7 \%$ put together either strongly disagree or disagree. Therefore, it can be said that the most of the institutions would've been 
more efficient if the tenets of impersonality and merit are not upheld in terms of appointments, posting and daily administration. The findings of the study show that;

- Recruitment and selection process of many employees in the institutions studied is mostly characterized by kinship and other in-group considerations like religion and region instead of merit.

- Some employees are wrongly placed in terms of job description just for them to be accommodated.

- Some erring employees go scot free because of their connection with some members of the top management.

- Absenteeism, late coming to work and lack of commitment to task are very common in the institutions studied.

- The institutions would've been very productive if the tenets of impersonality and merit are upheld in terms of appointments, postings and daily administration.

\section{Discussions of Findings}

From the findings, it can be seen that majority of the respondents agree or responded in the affirmative that recruitment and selection pattern of their institution is mostly characterized by kin-ship and other in-group considerations. This corroborates the earlier position of this study that the triangular fault lines of ethnicity, religion and region has become engrained into the fabrics of many public institutions determining the pattern of recruitment and selection of employees.

Additionally, across these institutions, there are instances where some employees are wrongly placed in terms of job description just for them to be accommodated since their recruitment and selection was determined by factors other than merit. Impliedly placing a round peck in a square hole will not only hamper the productivity of the institution but also undermine its efficiency. This position is exemplified by the fact that some of the institutions studied are substantially populated by employees revolving around the ethnicity, region and the religion of the chief executives of the members of the top management team of the institutions.

Based on the foregoing, majority of the respondents believes that some erring or defaulting employees always go scot free because of their connection with the members of the top management. Possibly, in a setting like this where the employees are mostly kinsmen or in one way or the other connected to the leaders of the institution, impartial and objective enforcement of rules and maintaining discipline and standard which are basic ingredients for efficiency may be very difficult. institutions.

Consequently, absenteeism, late coming to work and lack of commitment to task are recurring decimals in these

Finally, majority of the respondents agree that their institutions would've been more effective and productive if the tenets of impartiality and merit are upheld in recruitment and selection process or in terms of appointment, postings and daily administration. This corroborates the earlier position that sound recruitment and selection policy will enhance the efficiency of an organization.

\section{Conclusion}

This study further corroborates the general consensus in literature that recruitment and selection pattern among other factors determines the efficiency as well as the productivity of an organization. But as the study shows, in Nigeria, especially in the organizations studied, recruitment and selection process of many employees is mostly characterized by Parochial and in-group consideration like ethnicity, religion and regional cleavages. Consequently, impartial enforcement of rules and standards by the leadership of the institutions is undermined since most employees are in one way or the other connected or related to the leaders. Hence, absenteeism, late coming to work and lack of commitment to task are recurrent decimal in these institutions thereby undermining their ability to be effective and efficient.

In the final analysis, organizations would be more efficient and productive if the tenets of merit and impersonality are upheld in their recruitment and selection process. This by implication will mean that only the suitably qualified candidates are recruited or employed irrespective of their ethnic, religious or regional background. Consequently, they will bring to the table their expertise which is critical to organizational efficiency.

\section{References}

i. Anyango, E., Okibo, W. B., \& Muya, J. (2018). Effect s of Recruitment and Selection Criteria on Organizational Performance at Kisii University, Kenya. International Journal of Social Sciences and Information Technology. $4(10), 271-282$

ii. Armstrong, M. (2006). A Handbook of Human Resource Management Practice. 10 $0^{\text {th }}$ ed,Great $\quad$ Britain: Cambridge University.

iii. Barney, J. B. (1991). Firm resources and sustained competitive advantage. Journal of Management, $\quad$ 17(1), 99120

iv. Barney, J.B (2001). Resource-based theories of competitive advantage: A ten-year retrospective on the resource-based view. Journal of Management, 27(6), 643-650.

v. Boxall, P. \&Purcell, J., (2008). Strategy and Human resource management. Bristol: Palgrave.

vi. Brandford, S.A., \& McDonald, S. P. (2019). The Effect of Groupthink and Team-based Leadership on Institutional Productivity in Federal Tertiary Institutions in Taraba and Adamawa States. Unpublished Research Sponsored by Tertiary Education Trust Fund Nigeria.

vii. Delany, J. T., \& Huselid, M. A. (1996). The Impact of Human Resource Management Practices on Perceptions of Organizational Performance. Academy of Management Journal, 39, 949969. 
viii. Djabatey, E., N. (2012). Recruitment and Selection Practices of Organizations. A case study of HFC Bank (GH) Ltd. Unpublished thesis submitted to the institute of Distance Learning, Kwame Nkrumah University of Science and Technology. Ghana: Kwame Nkrumah University of Science and Technology.

ix. Ekwoaba, J. O., Ikeije, U. U., \& Ufoma, N. (2015). The Impact of Recruitment and Selection Criteria on Organizational Performance. Global Journal of Human Resource Management, 3 (2), 22-33

x. Ezeali, B. O. \& Esiagu, L.N (2010). Public personnel management: Human Capital management strategy in the $21^{\text {st }}$ century. Onitsha: Book Point Limited.

xi. Gamage, A.S. (2014). Recruitment and Selection Practices in Manufacturing SMEs in Japan: An analysis of the link with business performance. Ruhuna Journal of Management and Finance, 1(1), 37-52

xii. Gberevbie, D. E. (2010). Strategies for Employee Recruitment, Retention and Performance: Dimension of Federal Civil Service of Nigeria. African Journal of Business Management, $\quad 4,1447-1456$.

xiii. Guirdham, M. (2002). Interactive Behaviour at Work, $3^{\text {rd }}$ ed. Essex, Pearson Education Ltd .

xiv. Harel, G.H., \& Tzafrir, S.S. (1996). The effect of Human resource Management Practices on the perception of organizational and market performance of the firm. Human Resource Management, 38, 185-200

xv. Huselid, M. A., Jackson, S.E., \& Schuler, R. S. (1997). Technical and strategic human resource management determinants of firm performance. Academy of Management Journal, 40(1), 171-188. https//doi.org/10.2307/257025

xvi. Li, J. \& Karakowsky, L. (2002). Cultural malleability in an East Asian Context: An illustration between 34(2); 176201.

xvii. Ofori, D., \& Aryeetey, M. (2011). Recruitment and Selection Practice in Small and Medium enterprises. International Journal of Business Administration, 2(3):45-60.

xviii. Pfeffer, J. (1994). Competitive Advantage Through People. Boston, Harvard Business School Press.

xix. Price, A. (2004). Human Resource Management in a Business Context. $2^{\text {nd }}$ ed. London: Thomson Learning.

xx. Sims, R. L. (2009).Collective versus individualist national cultures. Business and Society, 48(1), 39-59.

xxi. Sakar, A., \& Kumar, S. (2007). Effective recruitment and selection: An approach toward model building. HRM Review, 7(7), 15-22.

xxii. Teixeira, A. (2002). On the link between Human Capital and Firm Performance; A Theoretical and empirical study. FEP Working Paper no. 121, Nov. p. 1-38

xxiii. Terpstra, D.E., \& Rozell, E.J., (1993). The relationship of staffing practices to organizational Level measuresof performance. Personnel Psychology, 46 (1), 27-48.https//doi.org/10.1111/j.1744-6570.1993.tb00866.x

xxiv. Tizhe, Z.C.O., James, O. \& Remilekun, G. (2017). Impact of Recruitment and Selection Strategy on Employees' Performance: A Study of Three Selected Manufacturing Companies in Nigeria. International Journal of Innovation an Economic Development, 3(3), 32-42

xxv. Tuckman, B. W. (1965). Developmental sequence in small groups. Psychological bulletin, 63(6), 384.

\section{Appendix}

- Table 1: Showing responses and their percentages for question 1

- Table 2: Showing responses and their percentages for question 2

- Table 3: Showing responses and their percentages for question 3

- Table 4: Showing responses and their percentages for question 4

- Table 5: Showing responses and their percentages for question 5

- Chart 1: Showing the distribution of responses for question 1

- Chart 1: Showing the distribution of responses for question 2

- Chart 1: Showing the distribution of responses for question 3

- Chart 1: Showing the distribution of responses for question 4

- Chart 1: Showing the distribution of responses for question 5 